\title{
Chewing-stick practices using plants with anti-streptococcal activity in a Ugandan rural community
}

\author{
Charles Okot Odongo ${ }^{1,2}$, Nathan Lubowa Musisi ${ }^{3}$, Paul Waako $^{1}$ and Celestino Obua ${ }^{1 *}$ \\ Department of Pharmacology and Therapeutics, School of Biomedical Sciences, Makerere University College of Health Sciences, Makerere University, \\ Kampala, Uganda \\ 2 Department of Pharmacology and Therapeutics, Faculty of Medicine, Gulu University, Gulu, Uganda \\ ${ }^{3}$ Department of Microbiology, Faculty of Veterinary Medicine, Makerere University, Kampala, Uganda
}

\section{Edited by:}

Anna Rita Bilia, University of Florence, Italy

\section{Reviewed by:}

Maria do Céu Gonçalves da Costa,

Laboratório Nacional de Energia e

Geologia, Portugal

Eleni Skaltsa, National and Kapodistrian

University of Athens, Greece

Funda Nuray Yalcin, Hacettepe

University Faculty of Pharmacy, Turkey

\section{${ }^{*}$ Correspondence:}

Celestino Obua, Department of

Pharmacology and Therapeutics,

School of Biomedical Sciences,

Makerere University College of Health

Sciences, Makerere University, Upper

Mulago Hill Road, P. O. Box 7072,

Kampala, Uganda.

e-mail: cobua@chs.mak.ac.ug
Background: The high dental disease burden in developing countries has created a need to explore and develop cheap and accessible methods of dental disease prevention. Traditional toothbrushes (chewing-sticks) prepared from specific plants have been used for dental hygiene for generations. When properly used, chewing-sticks may be as effective as synthetic toothbrushes. This study set out to describe traditional chewing-stick practices in a Ugandan rural community, and evaluate the antibacterial activity of two most commonly used plants. Methods: Interviews were done to identify chewing-stick plants and obtain socio-cultural information relating to the practice in two villages in rural Uganda. Field walks were done to pick and voucher the plants, for taxonomical identification and storage. For the two most reported plants, aqueous extracts were prepared and tested for antibacterial activity against Streptococcus mutans using the agar-well diffusion method. Results: Of the 21 key informants interviewed, all were using or had used chewing-sticks in the past. A total of eight plants were identified as sources of chewing-sticks, with Rhus vulgaris and Lantana trifolia most commonly mentioned. Chewingsticks were preferred over synthetic tooth brushes because they were less likely to traumatize the gums. Their use has been limited of recent due to scarcity of some plants. $R$. vulgaris and L. trifolia aqueous extracts showed antibacterial activity against $S$. mutans with mean diameters of inhibition of $24.33 \pm 0.58$ and $14.17 \pm 0.29 \mathrm{~mm}$ on Blood agar respectively, compared to benzyl penicillin control $30.67 \pm 0.29 \mathrm{~mm}$. Conclusion: $R$. vulgaris and $L$. trifolia are the most common sources of chewing-sticks for cleaning teeth in this community. The plants contain compounds that are active against $S$. mutans. These plants merit further studies as they are possible sources of cheap dental health care for the rural poor.

Keywords: chewing-sticks, Rhus vulgaris, Lantana trifolia, socio-cultural practices, aqueous extract, anti-streptococcal activity, Uganda

\section{INTRODUCTION}

Dental diseases pose a high burden to populations in developing countries mainly due to persistent poverty, ignorance, and resource constraints that have hindered effective health education and delivery of healthcare (Petersen et al., 2005). The Uganda National Oral Health Policy document (2007) recognizes that the dental care needs of the majority remain largely unmet because there are few professionals offering care. As a result, services are often too costly, scarce, or totally absent, especially in the rural areas of the country. This situation presents a need to explore, develop, and promote the use of locally available and accessible methods of dental disease prevention.

The use of plant-derived toothbrushes (chewing-sticks) is a common traditional dental care practice in many parts of the world. Within a given community, chewing-stick plants are often specific, but tend to vary from one culture to the next (Wu et al., 2001). As far back as the 1970s, it was suggested that the regular use of the African chewing-stick, acting as an antiseptic, may control the formation and activity of dental plaque and therefore reduce the incidence of gingivitis and possibly dental caries (Akpata and
Akinrimisi, 1977). Recent studies from different parts of the world appear to support the view that chewing-sticks may contain substances that promote dental health or substances that have antibacterial activity against plaque-forming bacteria (Sote and Wilson, 1995; Almas, 1999; Jagtap and Karkera, 1999, 2000; Ndukwe et al., 2005; Prashant et al., 2007). The use of chewing-sticks for cleaning teeth has been reported among several rural Ugandan communities (Eggeling, 1952; Kokwaro, 1976; Katende et al., 1998). However, some knowledge gaps do exist. This study, based on a rural community in Uganda was aimed at exploring and documenting socio-cultural aspects relating to the practice, identification of the plants used and evaluating the anti-streptococcal activity of aqueous extracts from the two most commonly used plants.

\section{MATERIALS AND METHODS INOUIRY ON SOCIO-CULTURAL CONSIDERATIONS, PLANT COLLECTION, AND IDENTIFICATION}

A community comprising two neighboring villages (Sango and Buwanda) in Buwama sub-county, Mpigi district was conveniently selected for the study. Village local council (L.C.) chairpersons were 
approached for permission to enter their areas of jurisdiction. They were also asked to nominate persons whom they regarded as elders within their communities. These "village elders" where taken as key informants because (as is in many African societies), such persons are normally custodians of traditional knowledge, cultural norms, and heritage. In addition, village elders were well suited to comment on any transition in dental health practices because they bare witness to the past and present situation. One-on-one interviews, employing a set of pre-tested open ended questions were used to obtain information on chewing-stick practices as well as identify the plants used. Collection and local identification of the plants was done during field walks, with the help of key informants and a village guide. Taxonomical identification was done with the help of a botanist and voucher specimens stored at the Makerere University Herbarium. A frequency table was generated for the plants mentioned. For the two most reported plants, aqueous extracts were prepared and tested against Streptococcus mutans, a key dental pathogen (Rolla et al., 1985).

\section{FORMULATION OF AQUEOUS EXTRACTS AND CONTROL SOLUTIONS}

Preparation of extracts was done according to the method of Prashant et al. (2007), with a few modifications as follows: fresh chewing-sticks were crushed using a metallic mortar and pestle and allowed to dry under shade for 2 weeks. Fifty gram powders were weighed and soaked in $100 \mathrm{ml}$ of de-ionized distilled water (obtained from Human Diagnostics, Uganda). The extraction process was allowed to progress for $48 \mathrm{~h}$ under refrigeration $\left(2^{\circ} \mathrm{C}\right)$. Occasional shaking of extraction flasks was done to facilitate the process. (In this method, it is assumed that the extraction process progresses until there is saturation of the aqueous phase). Finally, the filtered extracts were sterilized by passing each through a bacterial membrane filter $\left(0.45 \mu \mathrm{m}\right.$ pores, Ministart ${ }^{\oplus}$, Satorious, UK) under positive pressure. The filtrates were then labeled " $50 \mathrm{~g}$ extract" and stored under refrigeration $\left(2^{\circ} \mathrm{C}\right)$ awaiting antibacterial tests. Benzyl penicillin (Abbott Laboratories, India) at strength of $10 \mu \mathrm{g} /$ $\mathrm{ml}$ was chosen as positive control and prepared by diluting $0.5 \mu \mathrm{l}$ of a standard solution $(200 \mathrm{mg} / \mathrm{ml})$ with de-ionized distilled water to make a $10-\mathrm{ml}$ volume. De-ionized distilled water was used as negative control.

\section{ISOLATION OF THE TEST BACTERIA STREPTOCOCCUS MUTANS}

Streptococcus mutans was isolated from dental plaque donated by a consenting adult volunteer at Mulago Hospital dental clinic. The plaque was immediately transported to the laboratory in Stuart's transport medium (Sterilin ${ }^{\oplus}$, COPAN Innovations, UK) and inoculated on Mitis Salivarius agar (MS agar, Merck, Germany), a selective medium prepared according to Harold and Johannes (1975). Plaque suspension from the transport medium was streaked onto MS agar plates and aerobically incubated at $37^{\circ} \mathrm{C}$ for $48 \mathrm{~h}$ as described by Nomura et al. (2006). Pure plates were further prepared from well isolated colonies by sub-culturing and confirmed using appropriate biochemical tests.

\section{ANTIBACTERIAL ASSAY}

Antibacterial tests were carried out on 5\% sheep blood agar (Merck, Germany) using the agar-well diffusion method as described by Baker and Silverton (1985). All tests were set in triplicate and run concurrently. For each test plate, a loop-full of freshly cultured bacteria ( $24 \mathrm{~h}$ old) was transferred and surface-spread using a sterile cotton swab. Thereafter, four wells ( $4 \mathrm{~mm}$ deep) were sunk (equidistant from each other, about $10 \mathrm{~mm}$ from the edge of the plate) onto the agar using sterile borers ( $5 \mathrm{~mm}$ external diameter). The plates were then turned upside down and the wells labeled. The wells were then filled by sequentially transferring each of the extracts and controls using separate sterile pipette tips. Plates were aerobically incubated at $37^{\circ} \mathrm{C}$ for $48 \mathrm{~h}$. Growth inhibition zones around each well were measured using a pair of Vernier calipers and read off against a millimeter rule. Extracts were considered active if the inhibition zone diameter was $8 \mathrm{~mm}$ or more as recommended (Baker and Silverton, 1985).

\section{DATA ANALYSIS AND PRESENTATION}

Results of key informant interviews were analyzed using conventional content analysis as described by Abramson and Abramson (1999) and presented in a narrative form. Data from the antibacterial tests was analyzed using Microsoft Office Excel program (2003) and results presented as means or frequencies using tables where appropriate.

\section{ETHICAL CONSIDERATIONS}

Oral consent was obtained from all key informants and written informed consent was obtained from the dental plaque donor. The study was approved by the Research and Ethics Committee of Makerere University College of Health Sciences (No. REC REF 2009-020) and permission to conduct the study granted by The Uganda National Council for Science and Technology.

\section{RESULTS \\ PLANTS IDENTIFIED AS SOURCES OF CHEWING-STICKS}

During the interviews, a total of eight plants were identified as sources of chewing-sticks. Their identities and important details are shown in Table 1. The most frequently reported plants were Rhus vulgaris and Lantana trifolia. On this basis, they were selected for preparation of aqueous extracts on which antibacterial tests were performed.

\section{SOCIO-CULTURAL CONSIDERATIONS ON PREPARATION, USE, AND STORAGE OF CHEWING-STICKS}

A total of 21 key informants were interviewed of whom 12 were men and 9 women. From the interviews and discussions with key informants, it emerged that chewing-sticks were prepared mainly from branches of specifically known shrubs and trees listed in Table 1. Dracaena fragrans was the only plant from which chewingsticks were prepared from its young stems. The art of chewing-stick preparation and use was normally passed on from older community members to the young mainly by careful observation followed by constant practice. A few people were formally taught how to prepare chewing-sticks by an older member of the family.

During the interviews, it also emerged that a good chewing-stick was made from a branch of appropriate diameter $(0.5-1.0 \mathrm{~cm})$ and length $(15-20 \mathrm{~cm})$. This was cut off the plant and part or the entire bark peeled off, whichever one preferred. The denuded end was placed in the mouth and carefully chewed until it became soft, producing a brush-like fringe. Once the preparation was ready, it 
Table 1 | Plant sources of chewing-sticks in Sango and Buwanda villages as reported by key informants $(n=21)$.

\begin{tabular}{lllll}
\hline Botanical name & $\begin{array}{l}\text { Accession. } \\
\text { (voucher), no }\end{array}$ & Family & $\begin{array}{l}\text { No. of key } \\
\text { informants, no. (\%) }\end{array}$ & $\begin{array}{l}\text { Parts used to } \\
\text { prepare chewing-stick }\end{array}$ \\
\hline Rhus vulgaris Meikle & 37789 & Anacardiaceae & $16(76.2)$ & Branch \\
Lantana trifolia L. & 37792 & Verbenaceae & $12(57.1)$ & Branch \\
Mangifera indica L. & 37794 & Anacardiaceae & $9(42.9)$ & Branch \\
Enzzo & - & - & $9(42.9)$ & Stem/branch \\
Dracaena fragrans (L.) Ker Gawl & 37793 & Agavaceae & $6(28.6)$ & Stem \\
Cassia hockii De Wild & 37791 & Fabaceae & $7(33.3)$ & Branch \\
Citrus limonia (L.) Osbeck & 37788 & Rutaceae & $5(23.8)$ & Branch \\
Citrus sinensis (L.) Osbeck & 37790 & Rutaceae & $2(9.5)$ & Branch \\
\hline
\end{tabular}

"Name given in the local (Luganda) dialect since efforts to obtain plant sample for identification were futile.

was held between the thumb on one side, and the index and middle fingers on the opposing side. Others preferred to grip it between the thumb and little finger on one side, and the index, middle, and ring fingers on the opposing side. The soft brush-like end was placed against the tooth surface and put through a combination of vertical and horizontal strokes of motion. Teeth were brushed one at a time using fine gentle movements in order to avoid gum injury.

Most of those interviewed $(n=15)$ mentioned that skillful manual dexterity and plenty of time was required to correctly and effectively use the chewing-stick. Those who used chewingsticks did so mostly in the morning after waking up. A few people $(n=5)$ reported using them again in the late afternoons after a nap, or at bed time. It also emerged that no special beliefs, rituals, or religious considerations were associated with the preparation or use of chewing-sticks in this community. It was reported that chewing-sticks were normally stored in any convenient place as long as it was considered safe from human or animal interference. Such places included the top of cupboards or wardrobes $(n=14)$, above door panels, window frames, or ventilation holes $(n=9)$, or stuck between grass thatches on a roof $(n=5)$.

\section{FACTORS INFLUENCING THE USE OF THE CHEWING-STICK IN DENTAL CARE}

All the key informants interviewed were using the chewing-stick, or had used it at some point in the past. Several factors influencing the use of this dental care tool were mentioned. Most people $(n=16)$ cited ease of access as the reason to use the chewing-stick, because it was prepared and used at no cost. The purchase and use of the synthetic toothbrush along with toothpaste was considered an extra economic burden. However, some people have recently switched to using synthetic toothbrushes because the right chewing-stick plants were nowadays difficult to find around the vicinity of the homestead. Mentioned in this respect were $R$. vulgaris $(n=8)$, Mangifera indica $(n=5)$, and Cassia hockii $(n=5)$. One had to move a considerable distance to find them, which was often discouraging. Put in the words of one informant;

\footnotetext{
"Kakwansokwanso ta kya labika wanno kumpi, aba mwetaaga bamujja mu tale."
}

This literally means "Rhus species are no longer seen in the nearby areas, those who need it find it in the wild." Most interviewees $(n=15)$ claimed the small head of the chewing-stick made it possible to have better control during the tooth brushing act. By cleaning one tooth at a time, gum injury, and consequently bleeding, could be avoided; something that most users agreed was difficult to achieve with the synthetic toothbrush. For this reason, it was common advice for those suffering from bleeding gums to switch to the chewing-stick. The small head size of the chewingstick was also claimed to provide better cleaning access to posterior teeth, when compared with the synthetic toothbrush whose head was considered too large for easy access. However, no medicinal value was claimed in using any of the chewing-sticks in relation to dental diseases. The use of these particular plants as sources of chewing-sticks was driven by a feature that was common to all of them, i.e., the high fiber content of their stems and branches. Users explained that this property was responsible for the fine and soft brush-like bristles produced when the tip of stick was chewed. High fiber content also conferred resilience and prevented breakage of the handle during use.

From the interviews, it also emerged that the synthetic toothbrush was easy to use and required less time since it was possible to clean multiple teeth at a go. In addition, synthetic toothbrushes were also considered more durable when compared to chewingsticks $(n=18)$. These reasons tended to favor use of synthetic toothbrushes in an era where chewing-stick plants were becoming increasingly difficult to find.

\section{ANTIBACTERIAL ASSAYS}

Results of antibacterial tests are shown in Table 2. Both R. vulgaris and L. trifolia aqueous extracts demonstrated significant anti-streptococcal activity in this experiment.

\section{DISCUSSION AND CONCLUSION}

Eight plants were reported as sources of chewing-sticks in this study community. Three of these plants namely $R$. vulgaris, L. trifolia, and C. hockii have previously been documented as sources of chewingsticks in Ugandan communities (Eggeling, 1952; Kokwaro, 1976; Katende et al., 1998). The same plants were also most frequently mentioned in our study, consistent with the view that plants used as chewing-sticks tend to be specific, with their identities carefully passed on from one generation to the next (Wu et al., 2001). Fidelity to these plants may be due to possession of the right qualities necessary for effective tooth cleaning. Chewing-sticks were predominantly prepared from branches of shrubs and trees, a practice we 
Table 2 | Inhibition diameters of the 50-g extracts of Rhus vulgaris and Lantana trifolia against Streptococcus mutans on blood agar at $48 \mathrm{~h}$ incubation.

\begin{tabular}{lllll}
\hline Extract/control & \multicolumn{4}{c}{ Measured diameters of inhibition zones (mm) } \\
\cline { 2 - 5 } & 1st & 2nd & 3rd & Mean diameter (土SD) \\
\hline Rhus vulgaris & 24.0 & 25.0 & 24.0 & $24.33 \pm 0.58$ \\
Lantana trifolia & 14.0 & 14.5 & 14.0 & $14.17 \pm 0.29$ \\
Benzyl penicillin & 30.5 & 30.5 & 31.0 & $30.67 \pm 0.29$ \\
De-ionized water & 0.0 & 0.0 & 0.0 & 0.0 \\
\hline
\end{tabular}

consider bio-conservation friendly, because it is unlikely to threaten survival of the plants used. However, there is information that the ethnic Baganda boil and drink extracts from the roots of R. vulgaris as remedy for pregnancy-related abdominal pain (Katende et al., 1998), hypertension, and sugar disease (Mwebaza, 2005). The use of plant roots as a medicinal source threatens species' survival, and this may explain the present scarcity of some plants.

The aqueous extracts of both $R$. vulgaris and L. trifolia were found to be active against $S$. mutans, a key plaque-forming oral bacterium. This finding supports the use of these plants in oral hygiene since their potential anti-plaque effect is likely to complement the mechanical plaque-removing property of chewing-sticks. Presence of antibacterial activity in $R$. vulgaris extract is consistent with general antibacterial activity reported from other Rhus species in the past (Saxena et al., 1994; Abu-Shanab et al., 2005; Gundidza et al., 2008). This is however likely to be the first time a report is made on its effect on an oral pathogenic bacteria. The antibacterial principles in $R$. vulgaris probably belong to one or more of the following phytochemicals previously identified in R. vulgaris; essential oils, flavonoids, terpenes, and terpenoids (Okoli et al., 2002; Repetto and Liesuy, 2002; Mwebaza, 2005). From our study, it is not possible to attribute the antibacterial activity seen here to any particular phytochemical group.

From available literature, few studies have examined antimicrobial effects of L. trifolia. Cos et al. (2002), studying Rwandan medicinal plants, reported that extracts of L. trifolia were active

\section{REFERENCES}

Abramson, J. H., and Abramson, Z. H. (1999). Survey Methods in Community Medicine, 5th Edn. Edinburgh: Churchill Livingstone.

Abu-Shanab, B., Adwan, G., Abu-Safiya, D., Adwan, K., and Abu-Shanab, M. (2005). Antibacterial activity of Rhus coriaria L. extracts growing in Palestine. J. Islam. Univ. Gaza 13, 147-153.

Akpata, E. S., and Akinrimisi, E. O. (1977). Antibacterial activity of extracts from some African chewing sticks. Oral Surg. Oral Med. Oral Pathol. 44, 717-722.

Almas, K. (1999). The antimicrobial effects of extracts of Azadirachta indica (neem) and Salvadora persica (arak) chewing sticks. Indian J. Dent. Res. 10, 23-26.
Bairy, I., Reeja, S., Siddharth, Rao, P. S., Bhat, M., and Shivananda, P.G. (2002). Evaluation of antibacterial activity of Mangifera indica on anaerobic dental microflora based on in-vivo studies. Indian J. Pathol. Microbiol. 45, 307-310.

Baker, F. J., and Silverton, R. E. (1985). Introduction to Medical Laboratory Technology, 6th Edn. London: Butterworths \& Co. Ltd.

Cos, P., Hermans, N., De Bruyne, T., Apers, S., Sindambiwe, J. B., Vanden Berghe, D., Pieters, L., and Vlietinck, A. J. (2002). Further evaluation of Rwandan medicinal plant extracts for their antimicrobial and antiviral activities. J. Ethnopharmacol. 79, 155-163.

Eggeling, W. J. (1952). “Chapter 4: Shrubs," in The Indigenous Trees of the Uganda

against gram positive bacteria and Mycobacterium fortuitum. More recently however, Kisangau et al. (2007), working in Tanzania supported these findings when they reported antibacterial activity from the aqueous extract of the same plant. Prior to the two studies above, Rwangabo (1988) had also reported antimicrobial activity from a previously unreported flavonoid isolated from $L$. trifolia. This molecule was subsequently named umuhengerin. It is possible that the antimicrobial activity in L. trifolia seen in our study may be due to the presence of this compound.

Other chewing-stick plants mentioned in this study may also poses antibacterial effects as previous studies have indicated. In West Africa, antibacterial activity has been reported from the aqueous extract of Citrus sinensis chewing-sticks (Ndukwe et al., 2005). Work done on the aqueous extract of M. indica found antibacterial activity against several oral bacteria namely $S$. mutans, Prevotella intermedia, and Porphyromonas gingivalis (Bairy et al., 2002; Prashant et al., 2007). The compound mangiferin was found to be responsible for this activity. In India, both branches (Prashant et al., 2007) and leaves (Bairy et al., 2002) of M. indica (mango) are used in oral hygiene and care.

This study shows that $R$. vulgaris and L. trifolia are the most common sources of chewing-sticks in this community. These plants contain compounds that are active against $S$. mutans, and merit further investigation as they are possible sources of cheap dental health care for the rural poor.

\section{ACKNOWLEDGMENTS}

The authors wish to sincerely thank Dr. Mary Namaganda, from the Department of Botany, Makerere University, and Dr. Esther Katuura from the Natural Chemotherapeutics Research Laboratory, Ministry of Health (Uganda) for identification and authentication of the plants in this study. Mr. Aloysius Lubega, of the Department of Pharmacology and Therapeutics, Makerere University, is also appreciated for his work as a village guide and for providing language help during the interviews and field activities. The authors also thank all the local people who provided information about the plants that were studied. This work was funded through a grant from Gulu University, Uganda.

Protectorate, 2nd Edn, ed. I. R. Dale (Glasgow: The University Press), 43-49. Gundidza, M., Gweru, N., Mmbengwa, V., Ramalivhana, N. J., Magwa, Z., and Samie, A. (2008). Phytoconstituents and biological activities of essential oils from Rhus lancea L.F. Afr. J. Biotechnol. 7, 2787-2789.

Harold, J. V., and Johannes, V. H. (1975) Selective medium for the isolation of Streptococcus mutans. United States Patent No. 3890200.

Jagtap, A. G., and Karkera, S. G. (1999). Potential of the aqueous extract of Terminalia chebula as an anticaries agent. J. Ethnopharmacol.68,299-306. Jagtap, A. G., and Karkera, S. G. (2000) Extract of Juglandaceae regia inhibits growth, in-vitro adherence, acid production and aggregation of Streptococcus mutans. J. Pharm. Pharmacol. 52, 235-242.

Katende, A. B., Bukenya-Ziraba, R. Kakudidi,E. K.Z., and Lye, K.A. (1998). Catalogue of Economically Important Plants in Uganda. Botany Department, Makerere University, Kampala.

Kisangau, D. P., Lyaruu, H. V.M., Hosea, K. M., and Cosam, C. J. (2007). Use of traditional medicines in the management of HIV/AIDS opportunistic infections in Tanzania: a case of the Bukoba rural district. J. Ethnobiol. Ethnomed. 3, 29.

Kokwaro, J. O. (1976). Medicinal Plants in East Africa. Nairobi: East African Literature Bureau.

Mwebaza, N. (2005). Evaluation of Hypoglycemic and Antidiabetic Effects 
of Selected Medicinal Plants from Central Uganda. M.Sc. dissertation, Makerere University. Kampala. [Call No. M989e 2005].

Ndukwe, K. C., Okeke, I. N., Lamikanra, A., Adesina, S. K., and Aboderin, O. (2005). Antibacterial activity of aqueous extracts of selected chewing sticks. J. Contemp. Dent. Pract. 6, 86-94.

Nomura, R., Nakano, K., Nemoto, H., Fujita, K., Inagaki, S., Takahashi, T., Taniguchi, K., Takeda, M., Yoshihioka, H., Amano, A., and Ooshima, T. (2006). Isolation and characterization of Streptococcus mutans in heart valve and dental plaque specimens from a patient with infective endocarditis. $J$. Med. Microbiol. 55, 1135-1140.

Okoli, A. S., Okeke, M. I., Iroegbu, C. U., and Ebo, P. U. (2002). Antibacterial activity of Harungana madagascariensis leaf extract. Phytother. Res. 16, 174-179.
Petersen, P. E., Bourgeois, D., Ogawa, H., Estupinan, S., and Ndiaye, C. (2005). The global burden of oral diseases and risks to oral health. Bull. World Health Organiz. 83, 661-669.

Prashant, G. M., Chandu, G. N., Murulikrishna, K. S., and Shafiulla, M. D. (2007). The effect of mango and neem extract on four organisms causing dental caries: Streptococcus mutans, Streptococcus salivarius, Streptococcus mitis, and Streptococcus sanguis: an in-vitro study. Indian J. Dent. Res. 18, 148-151.

Repetto, M. G., and Liesuy, S. F. (2002). Antioxidant properties of natural compounds used in popular medicine. Braz. J. Med. Biol. Res. 35, 523-534.

Rolla, G., Scheie, A. A., and Ciardi, J. E. (1985). Role of sucrose in plaque formation. Scand. J. Dent. Res. 93, 105-111.
Rwangabo, P. C. (1988). Umuhengerin, a new antimicrobially active flavonoid from Lantana trifolia. J. Nat. Prod. 51, 966-968.

Saxena, G., McCutcheon, A. R., Farmer, S., Towers, G. H., and Hancock, R. E. (1994). Antimicrobial constituents of Rhus glabra. J. Ethnopharmacol. 42, 95-99.

Sote, E. O., and Wilson, M. (1995). In-vitro antibacterial effects of extracts of Nigerian tooth-cleaning sticks on periodontopathic bacteria. Afr. Dent. J. 9, 15-19.

Wu, C. D., Darout, I. A., and Skaug, N. (2001). Chewing sticks: timeless natural toothbrush for oral cleansing. J. Periodontal Res. 36, 275-284.

Conflict of Interest Statement: The authors declare that the research was conducted in the absence of any commercial or financial relationships that could be construed as a potential conflict of interest.

Received: 25 November 2010; accepted: 03 March 2011; published online: 16 March 2011.

Citation: Odongo CO, Musisi NL, Waako P and Obua C (2011) Chewing-stick practices using plants with anti-streptococcal activity in a Ugandan rural community. Front. Pharmacol. 2:13. doi: 10.3389/ fphar.2011.00013

This article was submitted to Frontiers in Ethnopharmacology, a specialty of Frontiers in Pharmacology.

Copyright () 2011 Odongo, Musisi, Waako and Obua. This is an open-access article subject to an exclusive license agreement between the authors and Frontiers Media SA, which permits unrestricted use, distribution, and reproduction in any medium, provided the original authors and source are credited. 